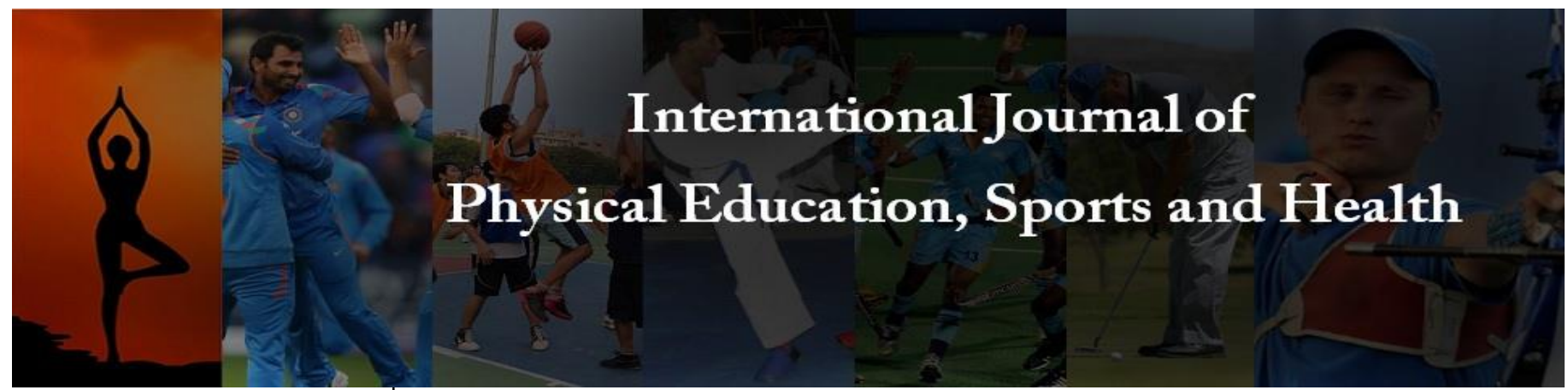

P-ISSN: 2394-1685

E-ISSN: 2394-1693

Impact Factor (ISRA): 5.38

IJPESH 2021; 8(1): 200-202

(C) 2021 IJPESH

www.kheljournal.com

Received: 01-11-2020

Accepted: 05-12-2020

\section{Aakif Javaid}

Research Scholar (M.Phil.), Department of Physical

Education, Rabindranath

Tagore University, Bhopal,

Madhya Pradesh, India

\section{Dr. Manoj Pathak}

Research Scholar (M.Phil.), Department of Physical

Education, Rabindranath

Tagore University, Bhopal,

Madhya Pradesh, India
Corresponding Author: Aakif Javaid

Research Scholar (M.Phil.), Department of Physical

Education, Rabindranath Tagore University, Bhopal, Madhya Pradesh, India

\section{Perception of feminist issues on unacceptability of coach's behaviour and unwanted experience in games and sports}

\author{
Aakif Javaid and Dr. Manoj Pathak
}

\section{Abstract}

The majority of research on unwanted sexual experiences has been conducted in family, workplace, and educational settings. Research in the sport context is still scarce but has grown steadily since the mid1980 s with qualitative and quantitative research addressing various aspects. These aspects include terms and definitions of different types and degrees of unwanted sexual experiences, descriptions of athletes' experiences, reported prevalence of different types of unwanted sexual experiences, the identification of causes and risk factors, and descriptions or proposals of prevention and intervention policies (Brackenridge, 2001 for a comprehensive overview of this research).

Hence the research scholar was keen interested to undertake the present study stated as "Perception of Feminist issues on unacceptability of coach's behavior and unwanted experience in games and sport". This chapter aims at summarizing the matters of the proceeding chapters. The main purpose of the study was to explore the perception of unwanted sexual harassment by the female athletes to the male coaches and also to compare the extracted four sub factors between the intercollegiate and interuniversity student athletes.

Keywords: Perception, feminist, behaviour, unwanted, experience

\section{Introduction}

Violence against women is a worldwide problem, occurring, to a greater or lesser degree, in all regions, countries, societies and cultures. It affects women irrespective of income, class, race or ethnicity. Since ages the position and status of women in India has been a very dynamic concept. Beginning from the Vedic period till today's time, the status of women has gone through enumerable changes. Violence against women is a big issue that encompasses multifarious acts of violence, abuse and torture against women in India

There are many women who have faced sexual harassment at some point of time, they had faced sexual harassment in metro trains, markets, educational institutes, workplaces, on social media websites and during morning walks. Whenever she is in her office or on her way to work. They're forced to keep quiet because if they make a noise or complaint about it they are subjected to worse crimes like assault (grievous, indecent, etc.) and rape, acid attack, etc. especially in India. (M. Pallavi Jane Pereira, Edmundo J. Rodrigues).

Methodology to achieve the purpouse of this study, one hundred eighty (180) students were randomly selected from the university of Kashmir and the data collection was done with the help of questionnaire on sport-specific Touch and Behavior versus Unwanted Intimacy from coaches, developed by Vanden Auweele (2006), was administered in this research.

\section{Source of data}

The data pertaining to this study were collected on 200 Female students hence all these female athletes were the source of data.

\section{Findings}

For the present study, the data was collected with the help of questionnaire on sport-specific Touch and Behavior versus Unwanted Intimacy from coaches, developed by Vanden Auweele (2006), was administered in this research. The data collected from the subjects has been statically analyzed and has been shown in separate tables given below. 
Table 1: Descriptive statistics on all the items of sport-specific touch and behavior versus unwanted intimacy from coaches questionnaire (Vanden Auweele (2006)

\begin{tabular}{|c|c|c|c|c|}
\hline Sl. No. & Items descriptions mean & & SD & $\mathbf{N}$ \\
\hline 1 & Coach gives you lift with his car/bike etc. & 2.93 & 1.69 & 180 \\
\hline 2 & Coach Stands/sits close to you while giving instruction & 2.29 & 1.59 & 180 \\
\hline 3 & Makes stereotypical/derogatory remarks on men and women & 4.11 & 1.30 & 180 \\
\hline 4 & Coach Comments on your physical appearance & 3.58 & 1.44 & 180 \\
\hline 5 & Coach Is staring at you during showering & 4.34 & 1.07 & 180 \\
\hline 6 & Coach Gives you a (romantic) present & 4.43 & 1.03 & 180 \\
\hline 7 & Coach Makes a sexual remark about you & 4.53 & .953 & 180 \\
\hline 8 & Coach Proposes a sexual encounter and issues a threat of rejection & 4.46 & 1.11 & 180 \\
\hline 9 & Coach Becomes a second family (surrogate parent) & 3.31 & 1.75 & 180 \\
\hline 10 & Coach showers with you and the other members of the team & 4.15 & 1.34 & 180 \\
\hline 11 & Coach Touches your shoulder/arm/hand during instruction & 2.93 & 1.66 & 180 \\
\hline 12 & Coach Laugh at you or your performance & 3.40 & 1.63 & 180 \\
\hline 13 & Coach Invites you home under pretext of sport matters & 3.72 & 1.56 & 180 \\
\hline 14 & Coach Is flirting with you and/or others in your team & 4.33 & 1.11 & 180 \\
\hline 15 & Coach Shows more attention to an individual athlete (instruction related) & 3.05 & 1.60 & 180 \\
\hline 16 & Coach Proposes sexual encounter, promising a reward in turn & 4.54 & .941 & 180 \\
\hline 17 & Coach Makes a sexist remark about you & 4.68 & .757 & 180 \\
\hline 18 & Coach Shows you his private parts & 4.76 & .660 & 180 \\
\hline 19 & Coach Makes flattering remarks about your appearance that leave you feeling uncomfortable & 4.43 & 1.10 & 180 \\
\hline 20 & Coach Kisses you or embraces you with a sexual undertone & 4.72 & .760 & 180 \\
\hline 21 & Coach Compliments or makes a comment about your figure & 4.40 & 1.11 & 180 \\
\hline 22 & Coach Tells a sexist joke & 4.56 & .879 & 180 \\
\hline 23 & Coach Gives more attention (not instruction related) to you than to your other teammates & 3.82 & 1.49 & 180 \\
\hline 24 & Coach Gives massage on the back side of your body & 3.52 & 1.59 & 180 \\
\hline 25 & Coach Gives massage on the front side of your body & 4.54 & .867 & 180 \\
\hline 26 & Coach sleeps in your room during tournament & 4.56 & .897 & 180 \\
\hline 27 & Coach is telling dirty jokes or stories & 4.60 & .836 & 180 \\
\hline 28 & Coach Invites you to the movies, dinner. & 4.41 & 1.11 & 180 \\
\hline 29 & Coach Makes sexual remarks about you & 4.62 & .853 & 180 \\
\hline 30 & Coach Asks you about your personal sex life, private sexual matters & 4.67 & .753 & 180 \\
\hline 31 & Coach Is staring at your breasts/your buttocks/your pubic area & 4.72 & .746 & 180 \\
\hline 32 & Coach Compliments to your clothing & 4.43 & 1.09 & 180 \\
\hline 33 & Coach Comes into your locker room before the time & 4.45 & 1.09 & 180 \\
\hline 34 & Coach touch your private parts or forces you to do something else & 4.59 & .888 & 180 \\
\hline 35 & Coach Calls you by a pet name (e.g. 'Honey') & 4.18 & 1.31 & 180 \\
\hline 36 & Coach ask you about your menstruation & 4.22 & 1.33 & 180 \\
\hline 37 & Coach Kisses you on your mouth & 4.66 & .819 & 180 \\
\hline 38 & Coach Touches you unnecessarily, deliberately (not instruction related) & 4.65 & .807 & 180 \\
\hline 39 & Coach calls you at home for non-sports related matter & 4.58 & .902 & 180 \\
\hline 40 & Coach Has an intimate relationship with an athlete under the legal age of consent & 4.73 & .671 & 180 \\
\hline 41 & Coach Has an intimate relationship with an athlete over the legal age of consent & 3.68 & 2.01 & 180 \\
\hline
\end{tabular}

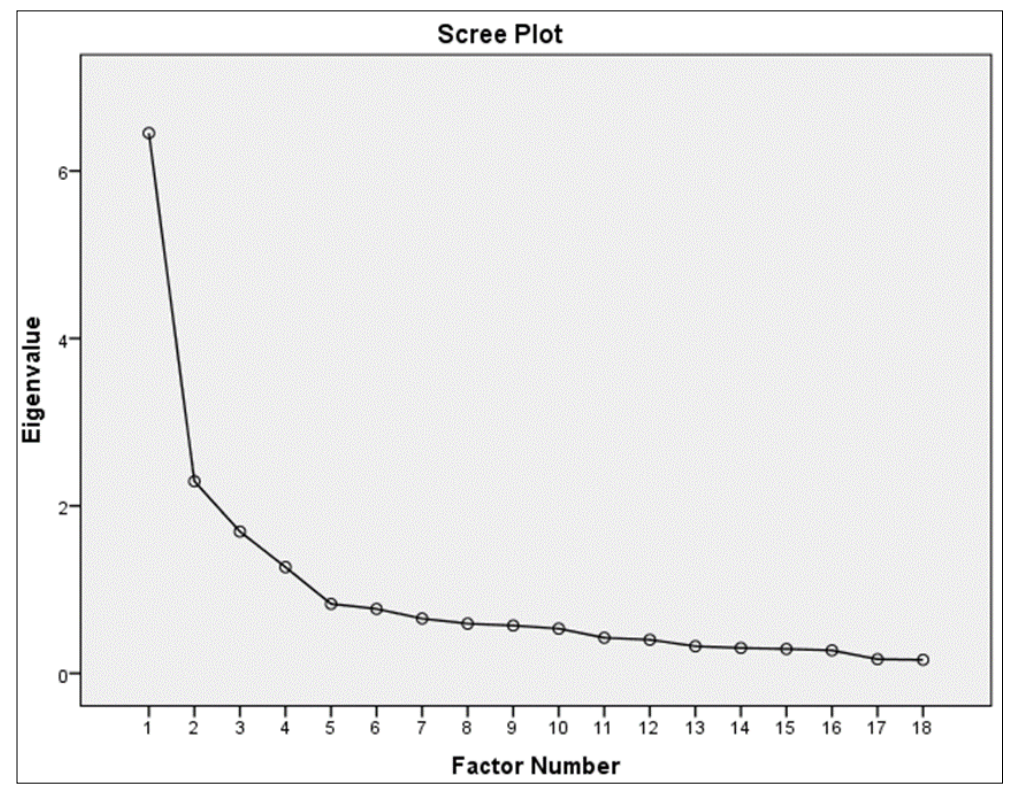

Fig 1: A scree plot technique based on eigenvalues signifying a sharp drop in variance accounted for the factors merely represent error or unique components 
The scree plot proposed by Cattell 1966 is another popular technique. The scree plot is a plot against the number of factors, and one looks for an "elbow" signifying a sharp drop in variance accounted for the factors merely represent error or unique components (R.G. Netemeyer, W.O. Bearden, S. Sharma 2003) or we can say it is also based on a plot of the eigenvalues associated with successive factors (R.F. DeVelliss 2003).

\section{Conclusion}

The results of this study suggest that, based on the reported prevalence, unwanted sexual experiences among studentathletes may not be uncommon.

\section{References}

1. Bart PB. A study of women who were both raped and avoided rape, Journal of Social Issues 1981;37(4):123137.

2. Benedict J. Athletes and Acquaintance Rape. London: Sage Series on Violence against Women 1998.

3. Brackenridge $\mathrm{CH}$. He owned me basically: Women's Experience of Sexual Abuse in Sport. International Review for the Sociology of Sport 1997;32(2):115-130.

4. Brackenridge CH. Exposing the 'Olympic family': A Review of Progress towards Understanding Risk Factors for Sexual Victimization in Sport. Paper Presented to Victimization of Children and Youth: An International Research Conference, University of New Hampshire, USA 2000.

5. Brackenridge $\mathrm{CH}$. Spoilsports: Understanding and preventing sexual exploitation in sport. London: Rutledge 2001.

6. Brannan C, Jones JR, Murch JD. Castle Hill Report: Practice guide. Shrewsbury: Shropshire County Council 1993.

7. Cense M, Brackenridge CH. Temporal and developmental risk factors for sexual harassment and abuse in sport, European Physical Education Review 2001;7(1):61-79.

8. Corby B, Doig A, Roberts V. Inquiries into child abuse. Journal of Social Welfare and Family Law 1998;20(4):377-95. 